\title{
On Artistic Conception for Landscape Design in Context of New-type Urbanization
}

\author{
Xiaoxi Zhang \\ Faculty of Arts \\ Hubei University \\ Wuhan, China \\ e-mail: 66835474@qq.com
}

\begin{abstract}
As China has a vast territory and countless small cities and towns and bears large gaps between different regions, landscape design of small cities and towns get a new connotation, owing to distinct geographical features formed by rich natural geomorphologic landscapes and human historical heritages. How to take a panoramic view of the situation, act according to local conditions and flexibly use the geographical features to create high-quality living environments for small towns and cities has become a hot topic among modern landscape designers.
\end{abstract}

Keywords—new-type urbanization; landscape design; design principles

\section{INTRODUCTION}

Along with the continuous improvement of people's living standards, material and spiritual needs of people have increased constantly. Their requirements for life have extended from small space to landscape style design in small cities and towns, design in small cities and towns, landscape planning and design in residential areas, street design, urban architectural design, parkland design, lake and river design, calamities preventing and fire-controlling system design in small cities and towns, human historical relics-preserving design in small cities and towns and interior design. Owing to continuous deepening of urban scientific theories, construction of small cities and towns has been distinguished from landscape design in small cities and towns. In the construction of small cities and towns, urban construction and social development are taken as the focus, for determining the direction for building cities and towns and constructing small cities and towns with distinct features [1]. Image shaping of small cities and towns is realized through landscape design of small cities and towns. Landscape design of small cities and towns is made based on the development of people' s material and spiritual demands to pursue harmonious coexistence between rapid development of urban construction and human living environment, and build sustainably-developed environment and human living landscapes with distinct regional features in urban areas.

\section{MANIFESTATION PATTERNS OF LANDSCAPE DESIGN ART In SMALl CitiEs AND TOWNS}

Combinations in nature, human culture, social ideology and other aspects have made small cities and towns have their unique styles. So as to give people a good impression and optimize 'human living environment', landscape designers should coordinate various elements and make various elements in a state of dynamic equilibrium, in order to fully manifest the landscape design art.

\section{A. Design Patterns of Natural Landscapes}

Concrete natural landscapes are a basis for features of small cities and towns, which are composed of mountains, water, vegetation, farmland and other parts. Within a specific space, each small city or town has its own particularly favorable natural conditions. Therefore, in landscape design, designers should make full use of favorable natural conditions of small cities or towns to incorporate integrate surrounding mountains, water and farmlands with cities or towns and manage small cities or towns, so as to achieve harmony and unity between different space environments and building groups and show the overall appearance of small cities or towns. In order to protect natural ecological balance from being broken and retain primitiveness of natural environment, attention should be paid to avoid unpractical arrangement of various landscape facilities regardless of unique environmental characteristics. For example, behaviors of "reclaiming lands from the sea" and "removing mountains to carve roads out" would not only increase construction costs, but also damage the environment. Moreover, landscape design in small cities and towns should be made according to local economic development situation. It is not rational to copy the landscape design pattern of large cities, in landscape design for small cities and towns. Landscapes for small cities and towns should be designed to be small and compact, with their own design features.

\section{B. Building Landscape Design Patterns}

Buildings have distinct regional, epochal and artistic characters. Different characteristics and styles of small cities and towns are formed mainly by different landscapes. 
Buildings are products of a combination of technology with art. Local features of small cities and towns are composed of natural and human cultural elements [2]. Building modeling and relevant building techniques are affected by local climates and geographical positions. Higher insulation requirements are put forward for building landscape design in Northern China, while higher ventilation requirements are made for building landscape design in Southern China.

Moreover, in the south, in order to cool off houses through sea breeze in summer, houses are designed to face the south or southeast, especially in coastal areas. In the meantime, typical houses in the north are designed to face the south, with balconies, doors and windows facing the south. Moreover, due to long-long and cold winter in the north, harms of accumulated snow and freezing and thawing should be given special attention. Given bad weathers in the north, attention should also be paid to prevent the damage of hail and sand blown by great wind.

In addition, streets in small cities and towns in the north are mainly wide and straight, because small cities and towns in the north are mostly sparsely populated. However, streets in small cities and towns in the south are mostly narrow, as the south is densely populated. Features of small cities and towns are mainly determined by their own characters. For example, urban construction should be made according to local folk customs, so as to create a favorable living environment. For example, Hui-style folk houses in Anhui, yurt in Inner Mongolia "Fig. 1" quadrangle courtyard in Beijing, stilted buildings in Guangxi and cave dwelling in Shaanxi have their own custom features.

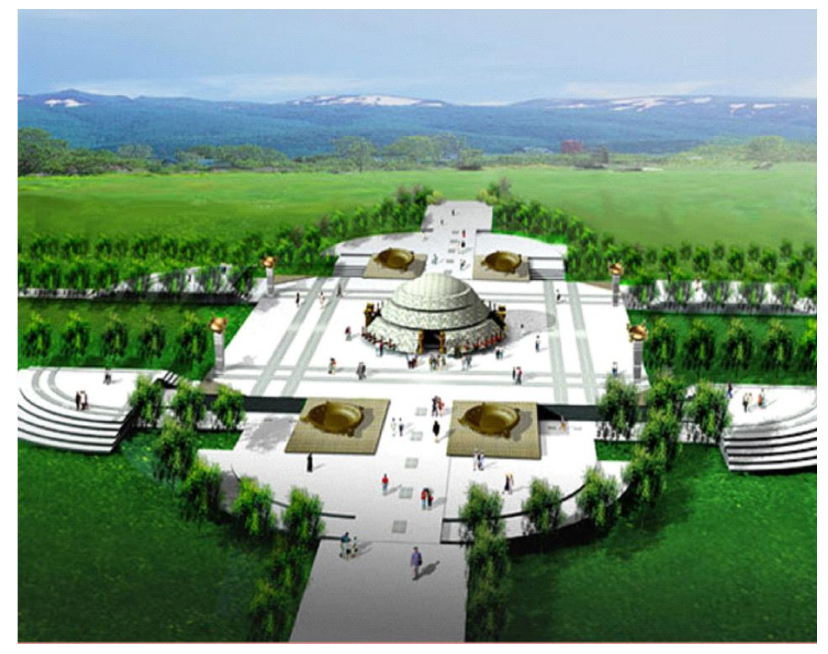

Fig. 1.

\section{Human Landscape Design Patterns}

The development history of a small town determines its formation and development "Fig. 2". Buildings, squares, gardens and featured landscapes in small cities and towns are shaped according to local historical traditions, customs, religious beliefs and other human environments. For example, to retain their historical and cultural connotations, small cities and towns should protect their human landscapes, such as food culture, religious culture, clothing culture, and folk arts and so on. Ethical and local features should be highlighted in human landscape design. Main features of landscapes in small cities and towns manifest as different ethical, epochal and regional characters. The Pathfinder in Shenzhen, the Earthquake Monument in Tangshan and other sculptures and murals show continuous innovation and indepth exploration of human artistic manifestation patterns. Moreover, traditional human landscapes should be inherited and protected, as they are quite precious, with great commemorative significance.

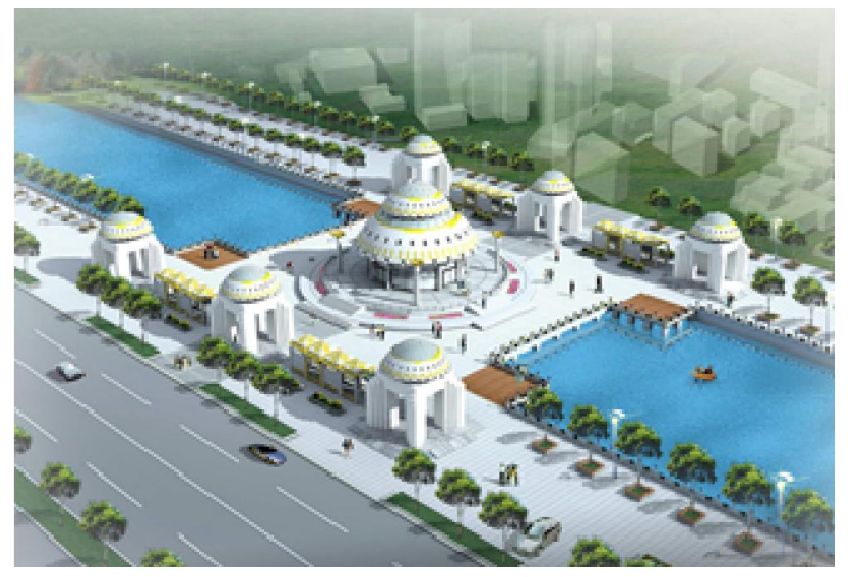

Fig. 2.

Along with China' s economic development, small cities and towns are facing urban renewals. How can we do to make a better protection and use of China' $s$ cultural heritages? So as to make small cities and towns have local features in their human environment building, it is quite essential to inherit and retain human resources in urban renewals of small cities and towns, as preservation of human cultural traditions is of great significance of landscape construction in small cities and towns. In landscape construction for small cities and towns, human cultural traditions should not be blindly retained. And it is quite necessary to absorb adsorb advanced design concepts to make an integration of the Chinese and Western culture and also cultures in different places in China. For example, churches are built in some cities of China, and the

"Single' s Day" as a new festival is celebrated. Only when these elements are linked together, can small cities and towns make a continuation of their cultural lifeline.

\section{LANDSCAPE DESIGN PRINCIPLES Of SMALl CITIES AND TOWNS}

Small town or city has its own unique characteristics and natural conditions. Historical relics and other landscape architectural elements are integrated into local landscape design to give full play to existing local characteristics and folk charm. Therefore, landscape construction should have some epochal and regional characters. 


\section{A. Taking a Panoramic view, Giving a Comprehensive Consideration and Adhering to Sustainable Development Concept}

Although China has a vast territory and abundant resources, it also suffers serious environmental pollution, desertification and a great shortage of land resources. Therefore, it is quite necessary to make a reasonable selection of landscape lands. However, at present, lands available in urban areas and agricultural lands are quite limited. In this case, it is quite necessary to reclaim wastelands into useful green and cultivated lands, fill up and take good advantage of low-lying and broke lands, and make positive transformations to make inferior lands into green lands meeting growing conditions of plants. Landscape lands widely distributed in small cities and towns have great potentials and a wide involvement range, so landscape lands should be used and planned, compatible with other plans, rather than independently, for joint planning, construction and development [3], such as industrial zone divisions, the road system, residential area planning and public construction divisions, and so on. Landscape design for small cities and towns should follow the basic design principle of "protecting environment, assimilating into environment, improving environment and maintaining sustainable development of environment" . For example, in the landscape design for small cities and towns, it is advised to design landscapes according to the low-carbon, green and ecological philosophy, which fully reflects requirements for resource conservation and environment protection, so as to develop ecological cities.

\section{B. Giving Consideration to Actual Situation}

Each small town or city has its own unique characteristics and natural conditions. Moreover, small cities or towns differ in the infrastructure and urban construction, planning development direction, economic systems, historical conditions and other aspects [4]. Therefore, landscapes in small cities and towns should be planned and designed according to actual situations. Manifestations patterns of themes of landscape design for different cities and towns are varied. For example, a small city or town can be designed to be surrounded by a moat or centered by a park. Landscape designers of small cities or towns should not blindly copy successful design cases, but give consideration to local geographical conditions and integrate natural forms into artificial forms, so as to create ideal landscape artistic forms.

\section{Reflecting Local Characteristics}

With different local conditions and customs, historical stories, folk culture, geographical environment and other factors, small cities and towns have their respective local characteristics [5]. Previous tree species, famous grass and trees and folklores have their respective styles. Historical relics and other landscape architectural elements are integrated into local landscape design to give full play to existing local characteristics and folk charm. For example, northern gardens are mostly royal gardens, highlighting axial symmetry of the layout, imitating natural landscapes in terms of the shape and having a large overall size. However, Northern gardens are mainly private gardens, with diverse layouts and delicate landscaping. Northern gardens enable people to see little in the large and show their respective merits. Garden landscapes in different areas of China can well preserve historical flavors, so that classical culture is well promoted, thus becoming unique local characteristics.

\section{Protecting cultural relics and integrating the ancient with the modern}

Most cities and towns are renovated on original sites. Walls, gates, drum towers, bell towers, ancient temples and other iconic buildings can still be seen in many cities and towns [6]. In urban construction, these ancient buildings will become irreplaceable precious relics and add mysterious colors to landscapes of modern small cities and towns. Therefore, it is irrational to remove old buildings in landscape construction of small cities and towns and blindly construct new buildings. "Fig. 3" It is advised that governments should retain some ancient buildings, while construct new ones, so as to integrate the ancient with the new.

\section{E. Making a reasonable distribution of functions and satisfying needs of different people}

Unlike big cities, small cities and towns are not densely populated, largely covered and in a land shortage [7]. Landscape design of small cities and towns requires a reasonable distribution of functions to satisfy demands of different people. Large-scale green lands can be cultivated in the center of cities or towns. The green lands can be set to be near residential areas to provide space to local residents for entertainment, so as to solve problems of inconvenient communication causes by population dispersion. In addition, iconic buildings or landscape corridors can be built in border areas of cities or towns, to leave a deep impression to visitors passing by. Local human landscapes should also be evacuated to gain a profound understanding of corresponding cities or towns.

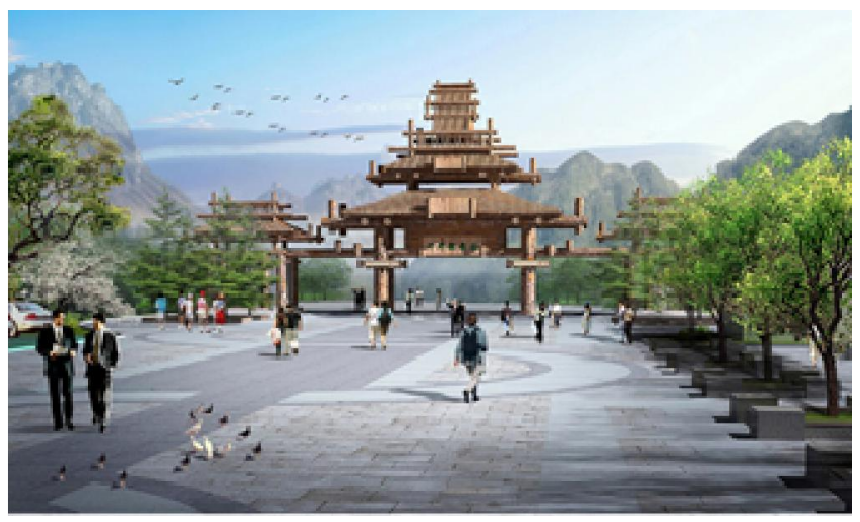

Fig. 3. 


\section{CONCLUSION}

Small cities and towns are inevitable products of China's economic development. Construction planning of small cities and towns are essential for the society to make progressive progresses. Creation through landscape environmental design for small cities and towns is a symbol for the development of small cities and towns, and is made for satisfying gradually extended demands of people. Therefore, landscape construction should have some epochal and regional characters. Only when landscape construction has distinct features, can landscapes meet continuouslyimproved aesthetic tastes of people in modern society. The long duration of landscape construction would encourage designers to make continuous explorations and innovation, so as to make landscapes of small cities and towns maintain their distinct characteristics, thus making landscape building art of small cities and towns keep abreast with the times.

\section{REFERENCES}

[1] Yao Chengming and Wen Jiangang, Preliminary analysis of image of small cities and towns and key elements of environmental landscape design-A case study of "No.5 Park" of Vanke in Shenzhen. City, 2010 (07).

[2] Zhang Tingwei, Problems of urban design in urban rapid development: Discussion about urban design principles. Urban Planning, 2001 (03).

[3] Jin Boling, Foundation and fields of the Chinese gardening science. Chinese gardening, 2004 (3), PP.01-04.

[4] Li Jiale, Modern landscape architecture and its formation. Chinese gardening, 2002 (4), PP. 3-6.

[5] Sun Peng and Wang Zhifang, Nature-complying urban river and water front landscape design . Urban planning, 2000 (9), PP.19-22.

[6] Liu Xiaotao, Discussion of issues related to river management in urban areas. Planners, 2001 (6), PP.66-69.

[7] Yu Kongjian and Li Dihua, Landscape design: A professional discipline and education . Beijing: China Building Industry Press, 2003 